\title{
IMPLEMENTASI KEBIJAKAN STANDAR NASIONAL SARANA DAN PRASARANA PEMBELAJARAN PRODI ADMINISTRASI PUBLIK FAKULTAS ILMU SOSIAL UNIMA
}

\author{
Jeane Elisabeth Langkai \\ jeanelangkai@unima.ac.id
}

\begin{abstract}
ABSTRAK
Penelitian ini dilaksanakan dengan tujuan melakukan analisis kebutuhan sarana dan prasarana program studi Ilmu Administrasi negara Fakultas Ilmu Sosial UNIMA melalui tersedianya: a). data profil prasarana dan sarana, baik software maupun hardware, b). mendeskripsi dan menganalisis profil prasarana dan sarana, baik software maupun hardware, yang perlu diberdayakan. Urgensi keutamaan penelitian adalah bahwa implementasi kebijakan yang diatur dalam Peraturan Menteri Riset, Teknologi, Dan Pendidikan Tinggi Republik Indonesia Nomor 44 Tahun 2015 Tentang Standar Nasional Pendidikan Tinggi program sarana dan prasarana merupakan jenis masalah sentral dalam pelaksanaan pembelajaran. Apabila kebijakan ini tidak diimplementasikan berdasarkan kebutuhan kelompok sasaran atau secara spesifik untuk kebutuhan pencapaian tujuan pembelajaran secara nasional, maka implementasi kebijakan ini akan cenderung berdampak pada belum tercapainya tujuan pembelajaran dan mengakibatkan rendahnya daya serap mahasiswa terhadap setiap pelaksanaan pembelajaran. Penelitian ini berkesimpulkan bahwa: sarana prasarana pada prodi Administrasi Publik yang menyangkut jumlah dosen, jumlah ruang kuliah, jumlah kursi, jumlah computer, jumlah LCD, genset belum seimbang dengan jumlah mahasiswa dan kebutuhan proses belajar mengajar. Untuk itu disarankan agar sarana dan prasara dilengkapi sesuai kebutuhan pelaksanaan proses belajar mengajar karena mahasiswa berhak mendapatkan pelayanan publik dalam bentuk tersedianya srana dan prasarana yang memadai untuk kenyaman belajar mengajar.
\end{abstract}

\section{Kata Kunci: Implementasi Kebijakan Standar Nasional, Program Sarana Prasarana}

\section{PENDAHULUAN}

Peraturan Menteri Riset, Teknologi, Dan Pendidikan Tinggi Republik Indonesia Nomor 44 Tahun 2015 Tentang Standar Nasional Pendidikan Tinggi ditetapkan dengan tujuan diantaranya untuk: a. menjamin tercapainya tujuan pendidikan tinggi dalam mencerdaskan kehidupan bangsa, memajukan ilmu pengetahuan dan teknologi; b. menjamin agar pembelajaran pada program studi, mencapai mutu sesuai dengan kriteria yang ditetapkan dalam Standar Nasional Pendidikan Tinggi; dan c. mendorong agar perguruan tinggi mencapai mutu pembelajaran, melampaui kriteria yang ditetapkan dalam Standar Nasional
Pendidikan Tinggi secara berkelanjutan. Standar Nasional Pendidikan Tinggi tersebut wajib dievaluasi dan disempurnakan secara terencana, terarah, dan berkelanjutan, sesuai dengan tuntutan perubahan lokal, nasional, dan global oleh badan yang ditugaskan untuk menyusun dan mengembangkan Standar Nasional Pendidikan Tinggi. Program Sarana dan Prasarana Pembelajaran merupakan kriteria minimal tentang sarana dan prasarana sesuai dengan kebutuhan isi dan proses pembelajaran dalam rangka pemenuhan capaian pembelajaran lulusan. Standar sarana pembelajaran sebagaimana dimaksud paling sedikit terdiri atas: a. perabot; b. peralatan pendidikan; c. media 
pendidikan; d. buku, buku elektronik, dan repositori; e. sarana teknologi informasi dan komunikasi; f. instrumentasi eksperimen; g. sarana olahraga; h. sarana berkesenian; i. sarana fasilitas umum; j. bahan habis pakai; dan k. sarana pemeliharaan, keselamatan, dan keamanan. Jumlah, jenis, dan spesifikasi sarana) ditetapkan berdasarkan rasio penggunaan sarana sesuai dengan karakteristik metode dan bentuk pembelajaran, serta harus menjamin terselenggaranya proses pembelajaran dan pelayanan administrasi akademik.

Beberapa permasalahan yang menyangkut implementasi kebijakan Kemenristekdikti tentang Standar Nasional Pendidikan Tinggi khususnya tentang sarana dan prasarana pembelajaran yakni belum optimalnya implementasi kebijakan program sarana dan prasarana pembelajaran yang ditandai dengan. belum memadainya: a perabot; b. peralatan pendidikan; c. media pendidikan; d. buku, buku elektronik, dan repositori; e. sarana teknologi informasi dan komunikasi; f. instrumentasi eksperimen; g. sarana olahraga; h. sarana berkesenian; i. sarana fasilitas umum; j. bahan habis pakai; dan k. sarana pemeliharaan, keselamatan, dan keamanan berdasar jumlah, jenis, dan spesifikasi sarana berdasarkan rasio penggunaan sarana sesuai dengan karakteristik metode dan bentuk pembelajaran, yang harus menjamin terselenggaranya proses pembelajaran dan pelayanan administrasi akademik.

Implementasi

kebijakan

Kemenristekdikti tentang Standar Nasional Pendidikan Tinggi khususnya tentang sarana dan prasarana pembelajaran sudah diupayakan tetapi hasil observasi pada Fakultas Ilmu Sosial menunjukkan bahwa dalam pelaksanaan pembelajaran di kelas belum tersedia kelas yang cukup memadai untuk menunjang proses belajar mengajar seperti papan tulis, LCD, listrik, WIFI (peralatan pendidikan, media pendidikan), belum tersedia buku, buku elektronik, dan repository, sarana teknologi informasi dan komunikasi, instrumentasi eksperimen, sarana olahraga, sarana berkesenian, sarana fasilitas umum (WC) yang dibutuhkan untuk terselenggaranya proses pembelajaran dan pelayanan administrasi akademik.

Data tersebut menunjukkan bahwa terjadi kesenjanan antara kebijakan yang diatur dalam Peraturan Menteri Riset, Teknologi, Dan Pendidikan Tinggi Republik Indonesia Nomor 44 Tahun 2015 Tentang Standar Nasional Pendidikan Tinggi khususnya program sarana dan parasarana pembelajaran dengan kondisi riil pada Fakultas Ilmu Sosial UNIMA lebih khusus Program Studi Ilmu Administrasi Negara yang melayani kurang lebih 662 mahasiswa dengan jumlah dosen 18 orang dan tenaga honoren 12 orang sementara ruang kuliah yang tersedia hanya 7 dengan 1 ruang pelaksanaan ujian seminar, (lihat borang bidang sarana prasarana bagian 6 Ilmu Administrasi Negar FIS UNIMA).

Penelitian ini dilaksanakan dengan kegiatan yakni: melakukan analisis kebutuhan sarana dan prasarana program studi Ilmu Administrasi negara Fakultas Ilmu Sosial UNIMA melalui tersedianya: a). data profil prasarana dan sarana, baik software maupun hardware, b). mendeskripsi dan menganalisis profil prasarana dan sarana, baik software maupun hardware,yang perlu diberdayakan

Penelitian ini bermanfaat bagi Fakultas Ilmu Sosial khususnya Ilmu Administrasi Negara dalam mengimplementasikan program Standar Nasional Pendidikan Tinggi khususnya sarana dan prasarana.

Masalah implementasi kebijakan yang diatur dalam Peraturan Menteri Riset, Teknologi, Dan Pendidikan Tinggi Republik Indonesia Nomor 44 Tahun 2015 Tentang Standar Nasional Pendidikan Tinggi program sarana dan prasarana merupakan jenis masalah sentral dalam pelaksanaan pembelajaran karena kebijakan ini dimaksudkan untuk menjamin tercapainya tujuan pendidikan tinggi dalam mencerdaskan kehidupan bangsa, 
memajukan ilmu pengetahuan dan teknologi, menjamin agar pembelajaran pada program studi, mencapai mutu sesuai dengan kriteria yang ditetapkan dalam Standar Nasional Pendidikan Tinggi; dan mendorong agar perguruan tinggi mencapai mutu pembelajaran, melampaui kriteria yang ditetapkan dalam Standar Nasional Pendidikan Tinggi secara berkelanjutan. Apabila kebijakan Standar Nasional Pendidikan Tinggi khususnya program sarana dan prasarana tidak diimplementasikan berdasarkan kebutuhan kelompok sasaran atau secara spesifik untuk kebutuhan pencapaian tujuan pembelajaran secara nasional, maka implementasi kebijakan ini akan cenderung berdampak pada: a) kurang efektifnya program, b) penggunaan uang negara yang mubasir karena pemenuhannya sangat minim, c) menurunnya pelaksanaan proses belajar mengajar, d) tidak produktifnya pencapaian tujuan nasional, dan tujuan Prodi akan mengakibatkan rendahnya daya serap mahasiswa terhadap setiap pelaksanaan pembelajaran.

Pemasalahan-permasalahan tersebut
apabila tidak diupayakan
penanggulangannya sesegera mungkin akan berdampak pada turunnya kualitas lulusan program studi dan mbasirnya dana negara yang dikeluarkan. Untuk itu perlu dioptimalkan upaya atau strategi implementasi kebijakan yang berdaya guna untuk pencapaian tujuan ditetapkannya standan nasional pendidikan tinggi.

\section{TINJAUAN PUSTAKA}

Hasil penelitian tentang yang dilakukan Martinus Tanggela (Jurnal Kebijakan dan Pengembangan Pendidikan Volume 1, Nomor 1 Januari 2013,26-34 ISSN: 2337-7623; EISSN: 2337-7615) tentang Analisis Implementasi Kebijakan Pengelolaan Sarana dan Prasarana Sekolah Di SMP Negeri 2 Batu menyimpulkan sebagai berikut: 1. Pengadaan sarana dan prasarana di SMP Negeri 2 Batu sangat bergantung pada kebijakan Pemerintah. 2 . Distribusi anggaran dapat bersifat swakelola atau melalui tender dengan sistem langsung. 3. Pemakaian sarana dan prasarana di SMP Negeri 2 Batu belum memiliki SOP dan administrasinya belum terintegrasi secara digital. 4. Pemeliharaan sarana dan prasarana di SMP Negeri 2 Batu dilakukan secara rutin, berkala, dan incidental. Efektivitas dan efisiensi pemeliharaan sarana dan prasarana sangat bergantung pada ketersediaan dana dan terkendala oleh tidak adanya pengelola khusus.

Waramatias tentang Evaluasi Implementasi Kebijakan Standar Sarana Dan Prasarana Laboratorium Fisika Sma Negeri 2 Kota Tangerang Selatan menyimpulkan bahwa komponen input, tidak menerapkan semua persyaratan dan ketentuan bangunan dan tidak memenuhi semua jenis dan jumlah perabot dan peralatan laboratorium, 2) pada komponen proses, pembangunan laboratorium tidak mengikuti semua bagian yang terdapat di dalam disain bangunan dan tidak semua jenis dan jumlah perabot dan peralatan laboratorium terpenuhi sesuai $\mathrm{RAB}$, dan 3) pada komponen output, bangunan laboratorium tidak menerapkan semua persyaratan dan ketentuan bangunan dan tidak semua jenis dan jumlah perabot dan peralatan laboratorium Fisika terpenuhi.

\section{Model-Model Implementasi Kebijakan Puvlik}

a). Van Meter dan Van Horn (1975).

Model tersebut menunjukkan bahwa keberhasilan implementasi kebijakan publik dipengaruhi oleh 1) kegiatan implementasi dan komunikasi antar organisasi yang terlibat dalam kebijakan publik, 2) Karakteristik implementor, 3) Keadaan ekonomi, sosial, dan politik disekitar kebijakan, 4) Kecenderungan prilaku implementor.

b). Model Mazmanian dan Sabatier.

Model tersebut mengklasifikasikan proses implementasi kebijakan ke dalam tiga karakteristik yaitu: 1) aspek Independen 
atau karakteristik Masalah, 2) aspek Intervening aau karakteristik kebijakan, 3) aspek dependen atau faktor ekstern yang berpengaruh pada implementasi kebijakan. Aspek independen yang menyangkut mudah atau sulitnya suatu masalah dikendalikan. Cakupannya adalah: 1) kesukaran teknis, 2) keragaman perilaku kelompok sasaran, 3) persentase kelompok sasaran dibandingkan dengan jumlah penduduk, dan 4) ruang lingkup perubahan perilaku yang diinginkan. Aspek intervening yakni kemampuan kebijakan untuk mensistematisasi proses implementasi kebijakan atau manajemen program kebijakan. Cakupannya adalah: 1) kejelasan dan konsistensi tujuan kebijakan, 2) alokasi sumberdana, 3) keterpaduan hirarki dalam dan di antara lembaga pelaksana, 4) aturan keputusan dari badan pelaksana, 5) rekruitmen pejabat pelaksana, dan 6) akses formal pihak luar. Aspek dependen yakni aspek di luar kebijakan yang mempengaruhi proses implementasi kebijakan. Cakupannya adalah: 1) kondisi sosial ekonomi dan teknologi, 2) dukungan publik, 3) sikap dan sumber daya yang dimiliki kelompok, 4) dukungan dari pejabat atasan, dan 5) komitmen dan kemampuan kepemimpinan pejabat pelaksana. Sedangkan aspek terikat yang ditunjukkan melalui tahapan dalam proses implementasi mencakup: 1) output kebijakan badan pelaksana, 2) kesediaan kelompok sasaran mematuhi output kebijakan, 3) dampak nyata output kebijakan, 4) dampak output kebijakan sebagaimana yang dipersepsikan, dan 5) perbaikan.

c) Jeane E Langkai (2015), menemukan prototipe implementasi kebijakan yang berdampak terhadap peningkatan kesejahteraan masyarakat di Kota Manado sebagai berikut:

Langkah pertama adalah analisis masalah secara metodologis dan ilmiah bersama antara birokrat dan ahli agar terjadi perpaduan antara praktisi dan tehnokrat dalam mengambil keputusan implementasi.
Analisis masalah dilakukan terhadap: a) faktor-faktod diluar kebijakan (independen) yang menyangkut kesukaran teknis implementasi karena pangaruh kebijakan nasioanal, faktor penyebab masalah kerusakan infrastruktur dan kemiskinan sasaran, perbandingan antara jumlah masyarakat miskin yang memiliki identitas sebagai penduduk di wilayah tersebut dengan populasi penduduk yang terdaftar secara resmi di daerah (bukan hasil rekayasa), ) perubahan perilaku sasaran dan masyarakat pada umumnya yang diinginkan dan dapat dicapai, b) Faktor Intervening atau komponen-komponen antara dalam implementasi kebijakan yang menyangkut, kejelasan tujuan dan sasaran kebijakan (standard), b) ketepatan alokasi dan ketersediaan sumberdana, c) disposisi , komitmen dan kompetensi implementor, dan d) kesiapan pihak terkait di luar struktur dalam berpartisipasi, c) Faktor Dependen atau faktor di luar sasaran (eksteren) yang menyangkut pemahaman implemenor, pihak terkait, dan masyarakat tentang latar belakang, tujuan dan sasaran kebijakan. Proses tersebut dilakkan agar dapat diketahui dan diprediksi dan dicarikan solusi tentang kekuatan, kelemahan, peluang dan ancaman terhadap implementasi. Langkah ke dua adalah praktisi dan tehnokrat merumuskan langkah-langkah strategi untuk implementasi kebijakan dalam bentuk sosialisasi dengan menggunakan media cetak dan elektronik, sarana-sarana sosial budaya, keagamaan yang sudah ada dimasyarakat. Langkah ke tiga adalah implementasi kebijakan, dengan melakukan evaluasi proses, akhir tahun anggaran.

Untuk menilai apakah kebijakan publik tersebut berdampak bagi publik, maka Dunn (2013: 610), mengemukakan beberapa kriteria diantaranya menilai: efektifitas, efisiensi, kecukupan, perataan, responsivitas, dan ketepatan. Sementara pendekatan yang dapat digunakan untuk mengevaluasi dampak kebijakan publik menurut Dunn (2013: 612) dapat dinilai dari tiga 
pendekatan yakni: Pendekatan untuk menilai tuju kriteria tersebut dilakukan melalui tiga pendekatan yakni: a) evaluasi semu. Bentuk evaluasi semu dengan metode deskriptif dimaksudkan agar diperoleh informasi yang valid dan reliabel tentang hasil dari implementasi kebijakan, b) Evaluasi formal dengan dimaksudkan agar diperoleh informasi yang valid dan reliabel mengenai hasil kebijakan secara formal yang telah dideklarasikan sebagai tujuan kebijakan dengan mengukur berdasarkan tujuan kebijakan, dan c) Evaluasi keputusan teoritis, agar diperoleh informasi yang valid dan reliabel tentang hasil kebijakan yang secara ekplisit yang dikehenaki pelaku kebijakan.

\section{METODE}

Penelitian menggunakan jenis penelitian survei. Subjek Penelitian, terdiri atas: 1). Peneliti, 2). Mahasiswa berprestasi, 3).pimpinan Prodi, 4). Dosen AN. Variabel Penelitian.Melakukan analisis:

kebutuhan, (2) karakteristik kebutuhan sarana dan prasarana FIS AN, (3) tujuan pengadaan sarana prasarana. Instrumen penelitian melakukan evaluasi mengenai: (1) kebutuhan sarana prasarana, (2) tujuan. Data dalam penelitian ini dianalisis menggunakan statistik deskriptif, data digunakan sebagai dasar untuk alur penelitian dibawab ini.

Penelitian dilaksanakan pada Fakultas Ilmu Sosial khususnya prodi Ilmu Administrasi Publik yang dilaksanakan dengan menggunakan metode survei dengan analsis data deskriptif kualitatif. Penelitian dilakukan dengan meakukan survei tentang profil sarana dan prasarana, análisis kebutuhan sarana dan prasarana, FGD antara peneliti, mahasiswa, pimpinan prodi dan dosen Ilmu Administrasi Negara. Melakukan deskripsi tentang kebutuhan sarana dan prasarana dan imlementasi kebijakan program sarana dan prasana berdasarkan Peraturan Menteri Riset, Teknologi, Dan Pendidikan Tinggi Republik Indonesia
Nomor 44 Tahun 2015 Tentang Standar Nasional Pendidikan Tinggi.

\section{HASIL PENELITIAN DAN PEMBAHASAN}

1. Keadaan mahasiswa

Mahasiswa prodi Administrsi Publik sampai dengan tahun 2018 berjumlah 840 mahasiswa yang terdiri dari semester I, III, V dan VII dibagi dalam kelas parallel A, B, C, D. Mahasiswa tahun akademik: 2012/2013 berjumlah 505, 2013/2014 berjumlah $628,2014 / 2015$ berjumlah 689 , 2015/2016 berjumlah 685, 2016/2017 berjumlah 685 dan 2017/2018 berjumlah 827.

Ratio antara jumlah mahasiswa dan jumlah dosen untuk ilmu social adalah menurut MENRISTEK adalah 1:30. Jika dihubungkan dengan jumlah mahasiswa dan jumlah dosen tetap maka 827: 15 berarti 55,1 persen berarti kekurangan tenaga dosen. Sebenarnya jumlah dosen yang dibutuhkan adalah 27 sampai dengan 28 dosen. Untuk menyelesaikan masalah tersebut maka prodi Administrasi Publik menggunakan tenaga dosen luar biasa untuk bidang studi yakni berjumlah 7 dosen. Dari data tersebut terungkap bahwa Prodi Administrasi Publik kekurangan tenaga dosen.

2. Keadaan tenaga Akademik/Dosen

Jumlah dosen tetap 15 dosen dengan perincian 2 guru besar, 10 Doktor, 3 sementara studi S3 dan dosen tidak tetap berjumlah 33 dosen dengan perincian: 1 guru besar, 7 doktor dan 25 Magister.

3. Sarana Ruang Kerja Dosen

Berdasarkan data tersebut pada sarana ruang dosen maka menunjukkan bahwa untuk melaksanakan aktivitas tugak poko dan fungsi dosen maka dosen Prodi Administrasi Publik kekurangan ruang kerja atau dapat dikatakan ruang kerja dosen belum memadai karena satu ruangan ditempati oleh 3-4 dosen. 
4. Sarana dan parasarana penunjang kegiatan akademik

Ruang kuliah Prodi Administrasi Publik berjumlah 7 ruangan dengan total 527 mahasiswa. Perkuliahan dibagi dalam kelas paralel sebagai konsekwensi dari jumlah dosen dan jumlah ruang kuliah yang belum memadai. Akibatnya mahasiswa disesal dalam ruangan yang terdiri dari kelas $\mathrm{AD}$ dan $\mathrm{BC}$ dan untuk mahasiswa semester I kurang lebih 100 orang menempati ruang yang idealnya hanya untuk 50 mahasiswa. Kondisi ruang kuliah yang padat berdampak pada belum nyamannya mahasiswa mengikuti setiap proses perkuliahan. Untuk masuk keluar saja sulit, mahasiswa yang minta isin keluar terpaksa sangat mengganggu proses belajar mengajar karena harus mengeser mahasiswa lain yang sedang serius mengikuti proses belajar.

Wawancara dengan beberapa mahasiswa tentang kenyamanan mengikuti proses perkuliahan ditinjau dari kepadatan dalam kelas mereke menakui bahwa keadaan kelas yang sangat padat membuat mereka merasa tidak nyaman mengikuti proses perkuliahan.

Data tersebut menunjukkan bahwa sebenarnya untuk setiap semester yakni 1,3, 5 dan 7 diperlukan 4 ruang kuliah, atau dibutuhkan 16 ruang kuliah, sementara yang tersedia hanya 7 ruang kuliah. Kondisi ini menunjukkan bahwa sarana dan prasarana dilihat dari jumlah ruang kuliah dapat dikatakan belum memadai.

Ruang Laboratorium hanya tersedia 1 ruangan dan dijejali dengan sejumlah computer dan dari hasil pengamatan menunjukkan bahwa kondisi tersebut belum menunjang setiap kali mahasiswa melakukan pratikum. Apalagi dengan pembagian kelas parallel maka tidak bias mahasiswa menggunakan ruangan dan computer karena ratio antara luas ruangan dan jumlah mahasiswa tidak memadai. Kondisi tersebut berdampak pada ketidak nyamanan mahasiswa dalam mengikuti

\begin{tabular}{|l|c|l|}
\hline $\begin{array}{l}\text { Ruang Kerja } \\
\text { Dosen }\end{array}$ & $\begin{array}{l}\text { Jumlah } \\
\text { Ruang }\end{array}$ & $\begin{array}{l}\text { Jumlah } \\
\text { Luas } \\
\left(\mathbf{m}^{2}\right)\end{array}$ \\
\hline $\begin{array}{l}\text { Satu ruang } \\
\text { untuk lebih } \\
\text { dari 4 dosen }\end{array}$ & $\mathbf{( 2 )}$ & \multicolumn{1}{|c|}{ (3) } \\
\hline $\begin{array}{l}\text { Satu ruang } \\
\text { untuk 3 - 4 } \\
\text { dosen }\end{array}$ & 24 & 54 \\
\hline $\begin{array}{l}\text { Satu ruang } \\
\text { untuk 2 dosen }\end{array}$ & - & (c) - \\
\hline $\begin{array}{l}\text { Satu ruang } \\
\text { untuk 1 dosen } \\
\text { (bukan } \\
\text { pejabat } \\
\text { struktural) }\end{array}$ & 2 & (d) 12 \\
\hline TOTAL & & (t) 90 \\
\hline
\end{tabular}

kegiatan pratikum untuk mata kuliah computer.

Selanjutnya untuk computer yang tersedia belum bias digunakan sebagaimana mestinya karena terdapat computer yang sudah rusak dan mahasiswa harus bergantian menggunakannya dan belum cocok dengan alokasi waktu yang tersedia.

Tersedianya ruang perpustakaan atau ruang baca tetapi belum dilengkapi dengan meja dan kursi. Akibatnya mahasiswa yang mau menggunakan ruang baca terpaksa belum menggunakannya karena belum tersedia meja dan kursi yang cukup.

Ruang seminar, ruang ujian hasil dan ujian komprehensif menggunakan ruang yang sama dan sangat kecil dan untuk tiga kegiatan tersebut terpaksa dilakukan secara bergantian dan mahasiswa yang

ingin mengikuti kegiatan seminar, ujian hasil belum dapat mengikutinya dengan baik karena belum tersedi kursi dan meja, akibatnya mahasiswa yang ingin mengikutinya terpaksa harus berdiri.

Dari jumlah printer yang tersedia dan yang masih dapat digunakan sebagaimana yang diinformasikan oleh pimpinan program sudi hanya tersedia 1 (satu) unit dan yang dapat dipakai sekarang dibeli dengan swadaya patungan 
antara dosen dn alumni. Jumlah ini belum sesuai dengan kapasitas mahasiswa yang berjumlah 827. LCD sebagai sarana dan prasarana yang menujang proses belajar mengajar hanya tersedia 1(satu) sementara setiap harinya dibutuhkan 4 LCD yang harus dioperasionalkan sehubungan dengan kegiatan proses belajar mengajar. Sebagai akibatnya dosen berebutan untuk memperoleh LCD dan untuk kelas kelas lainya terpaksa dilayani dengan hanya menggunakan papan tuls atau white board. Dosen dalam melaksanakan perkuliahan diajibkan menggunakan power point sementara LCD yang tersedia hanya satu buah. Akibatnya dosen menjadi malas prodi belum memiliki genset. Jika terjadi hal seperti ini maka kuliah dihentikan karena kekurangan penerangan. Ditambah lagi ketika hujan deras maka kuliah dihentikan karena prodi belum memiliki menggunalan power pint karena pada kenyataannya hanya tersedia satu LCD.

Dalam pelaksanaan perkuliahan kadang terjadi listrik mati dan kadang gelap karena pengaruh cuaca hujan sementara wairles. Belum tersedianya sarana dan rasarana yang memadai pada Prodi Administrasi Publik, jika belum diatasi sesegera mungkin akan berdampak pada menurunya semangat belajar mahasiswa dan semangat mengajar dosen dan kondisi ini bertentangan dengan tujuan dari Peraturan Menteri Riset, Teknologi, Dan Pendidikan
Tinggi RI Nomor 44 Tahun 2015 Tentang Standar Nasional Pendidikan Tinggi. Peraturan tersebut menyebutkan bahwa standar sarana dan prasarana pembelajaran merupakan kriteria minimal tentang sarana dan prasarana sesuai dengan kebutuhan isi dan proses pembelajaran dalam rangka pemenuhan capaian pembelajaran lulusan. Standar prasarana pembelajaran paling sedikit terdiri atas: lahan, ruang kelas, perpustakaan, laboratorium, tempat berolahraga, ruang untuk berkesenian, ruang unit kegiatan mahasiswa, ruang pimpinan perguruan tinggi, ruang dosen, fasilitas umum. Fasilitas umum meliputi: jalan, air, listrik, jaringan komunikasi suara, dan data.

\section{KESIMPULAN DAN SARAN}

Berdasarkan hasil penelitian tersebut maka disimpulkan bahwa: sarana prasarana pada prodi Administrasi Publik yang menyangkut jumlah dosen, jumlah ruang kuliah, jumlah kursi, jumlah computer, jumlah LCD, genset belum seimbang dengan jumlah mahasiswa dan kebutuhan proses belajar mengajar.

Untuk itu disarankan agar sarana dan prasara dilengkapi sesuai kebutuhan pelaksanaan proses belajar mengajar karena mahasiswa berhak mendapatkan pelayanan publik dalam bentuk tersedianya srana dan prasarana yang memadai untuk kenyaman belajar mengajar.

\section{REFERENSI}

Akib, Haedar. 2009. Artikulasi Perkembangan Ilmu Administrasi Publik, Jurnal Baca Edisi: Vol. 2 No. 3, Pusat Kejian Lembaga Penelitian Universitas Pepabri Makasar. 2010, Implementasi Kebijakan : Apa, Mengapa, dan Bagaimana, Jurnal Administrasi Publik, Volume 1 No. 1, Pusat Kajian Lembaga Penelitian UNEM. Efektivitas Implementasi dan Dampak Kebijakan dalam Konteks Desentralisasi Pemerintahan

Dunn William N. 2013. Pengantar Analisis Kebijakan Publik. Yogyakarta:

Gadjah Mada University Press.

Dye,Thomas R, 1995, Understanding Public Policy,New Jersey; Prentice Hall

Mazmanian Daniel and Paul A. Sabatier (eds). 1981. Effective Policy 
Implementation. Lexington Mass DX: Health.

Martinus Tanggela, 2015, Analisis Implementasi Kebijakan Pengelolaan Sarana dan Prasarana Sekolah Di SMP Negeri 2 Batu, Jurnal Kebijakan dan Pengembangan Pendidikan Volume 1, Nomor 1 Januari 2013,26-34 ISSN: 2337-7623; EISSN: 2337-7615)

Nugroho Riant. 2006. Kebijakan Publik: Untuk Negara-Negara Berkembang. Jakarta: Elex Media Komputindo Kelompok Gramedia.

............. 2011. Public Policy. Jakarta: Elex Media Komputindo Kelompok Gramedia.

Peraturan Menteri Riset, Teknologi, Dan Pendidikan Tinggi RI Nomor 44 Tahun 2015 Tentang Standar Nasional Pendidikan Tinggi

Prodi Administrasi Publik, Borang Akreditasi, 2018

Sugiyono, 2008. Metode Penelitian Kualitatif, Kuanitatif, dan R Dan D. Alfabeta Bandung.

Van Metter, D.S and C.E Van Horn. 1978. The Policy Implementation Process: A Conceptual Framework, Administration and Society.

Jeane Elisabeth Langkai, 2014, Implementasi Kebijakan Penganggur Terbuka Di Kota Manado, Jurnal UNIMA

2014, Model Implementasi Kebijakan PBL Dalam Mensejahterakan Masyarakat di Kota Manado, Jurnal UNM

, 2015, Determinan Implementasi Kebijakan PBL di Kota Manado, Jurnal MIIS India 2015

2016 Dampak Implementasi Kebijakan PBL terhadap Kesejahteraan Masyarakat di Kota Manado, Mediterranean Journal of social sciences vol 7 (2)

Waramatias Jurnal Kebijakan dan Pengembangan Pendidikan Volume 1, Nomor 1 Januari 2013,26-34 ISSN: 2337-7623; EISSN: 2337-7615) tentang Evaluasi Implementasi Kebijakan Standar Sarana Dan Prasarana Laboratorium Fisika Sma Negeri 2 Kota Tangerang Selatan. 